\title{
Replantation of Nine Fingers in a Patient A case report
}

"Rahul K. Patil, Gopal Malhotra, Srinivasan Venugopal, Emad Salah, Abdelfattah Ramadan

$$
\text { إعادة زراعة تسعة أصابع في مريض تقرير حالة }
$$

$$
\text { راهول كريشنارو باتيل، جويال مالهوترا، سرينيفاسان فينوغوبال، عماد صلاح، عبد الفتاح رمضان }
$$

ABSTRACT: Amputation of multiple fingers of both hands is a rare and serious injury. We report a case of a 41-yearold male patient who presented to Khoula Hospital, Muscat, Oman, in 2015 with the amputation of nine fingers due to a workplace injury. With two teams working in tandem, all the amputated fingers were re-attached. A total of seven fingers survived and the patient regained reasonable functionality of his hands. To the best of the authors' knowledge, this is the first case of several finger amputations in Oman.

Keywords: Fingers; Traumatic Amputation; Crush Injuries; Replantation; Case Report; Oman.

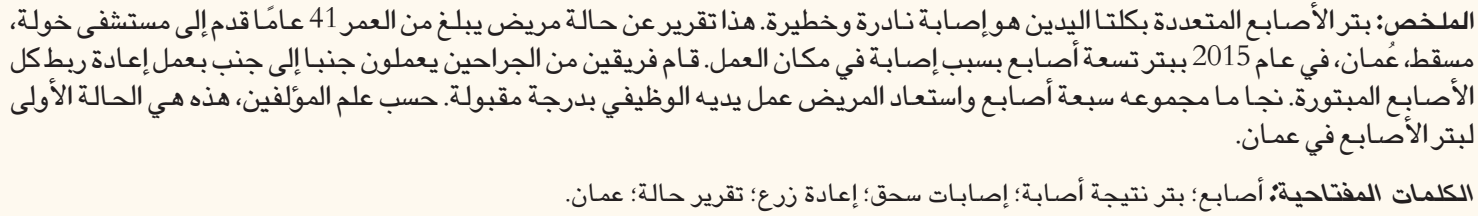

$\mathrm{I}$ NDICATIONS FOR REPLANTATION HAVE EVOLVED since the possibility of replantation of an amputated finger became a reality in the late nineteenth century. ${ }^{1}$ Thumb, distal digital amputations, amputations in children and proximal amputations such as through the hand and distal forearm are currently considered indications for replantation. ${ }^{2}$ In addition, multi-finger amputation is an indication for replantation, although the incidence of such injuries is relatively low. ${ }^{3}$ The overall function of the hand improves following replantation of these parts and outweighs the risk associated with the stiffness of the replanted parts. ${ }^{4}$

Single finger amputations with crush or avulsion type injuries and amputations proximal to the insertion of the superficialis tendon are relative contraindications for replantation. These fingers are unlikely to function well following replantation and may compromise the overall hand function. ${ }^{3}$

Multi-finger replantation is challenging even for experienced microsurgeons. It is time consuming and involves extensive planning. The access incisions and sequence of repair of structures requires careful appraisal depending upon the ischaemia time. Amputation of nine fingers in a single patient is quite rare; we report the first case of a nine-finger replantation in Oman. The procedure and functional outcome is presented three years after the replantation surgery.

\section{Case Report}

A 41-year-old male patient presented to Khoula Hospital, Muscat, Oman, in 2015 with nine amputated fingers. While operating a paper cutting machine, eight of the patient's fingers were amputated through the proximal phalanges, while the right thumb was amputated through the distal phalanx [Figure 1]. The parts were well preserved and were reasonably clean cut. The patient was haemodynamically unstable with a blood pressure of 90/60 mm most likely due to bleeding from the amputation sites. Further assessment ruled out any associated injury.

The bleeding was controlled with pressure dressing and hand elevation and the patient was adequately returned to a normal haemodynamic state. Appropriate consent was obtained once the patient was stabilised. The total ischaemia time when the patient was received at the hospital was approximately two hours and 30 minutes. X-ray images of the hands with amputated parts are shown in Figure 2. The amputated parts were transferred to the operation theatre to facilitate exploration of the structures while the patient was being prepared for replantation surgery.

Two separate teams began microscopic dissection of the amputated fingers. The procedure involved debridement and exploration through mid-lateral incisions for identification of the tendons, nerves and vessels of 


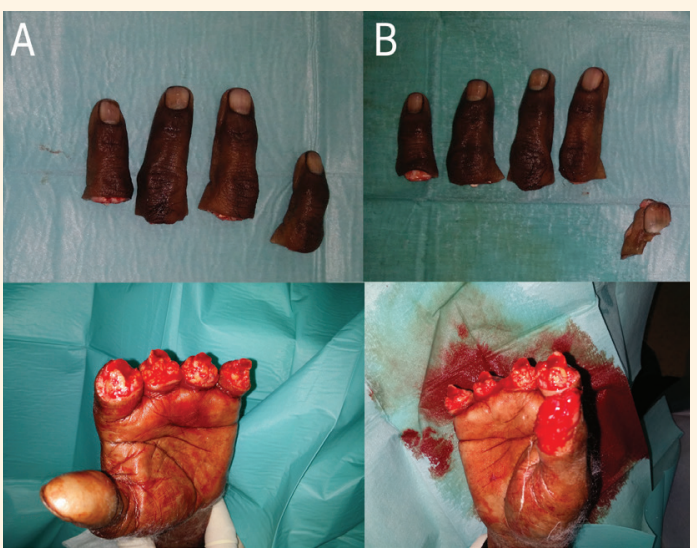

Figure 1: Photograph of multiple finger amputations of a 41-year-old male patient following a workplace injury showing the amputations on the (A) left hand and (B) right hand.

the amputated parts. Adequate length of these structures was exposed for later repair and replantation. The bone of each amputated finger was prepared by passing 1.2 $\mathrm{mm}$ Kirschner wires in a retrograde manner through the distal parts for later skeletal stabilisation. The patient was put under general anaesthesia and his hands were prepared for the procedure which was performed on both hands simultaneously.

Through mid-lateral incisions on the radial and ulnar side of the stumps of each finger, the structures including bone, tendons, vessels and nerves were identified and prepared. Healthy vessels were found at the bases of all fingers distal to the bifurcation of common digital vessels. Proximal phalanges were adequately shortened in each of the finger stumps to achieve primary soft tissue closure without tension. The amputated fingers were then aligned with the stumps and the prefixed wires were driven into the proximal stumps to achieve skeletal stabilisation. The flexor digitorum profundus tendons in all fingers were repaired. Repair of the radial and ulnar digital nerves followed the tendon repair with 9-0 nylon sutures.

After appropriate preparation, the radial and ulnar digital arteries for each finger were repaired. Following the repair of the arteries, 5,000 international units of intravenous heparin was administered and the arterial clamps were released. Extensor tendon repair was done on the dorsal aspect of the fingers and two dorsal subcutaneous veins were repaired for each of the involved fingers. The right thumb pulp was defattened and replaced by a full thickness graft. After the initial two and a half hours to reach the hospital (cold ischaemia time), there was further delay of six hours (warm ischaemia time) until the arterial clamps were released. The entire procedure took approximately 14 hours to complete.

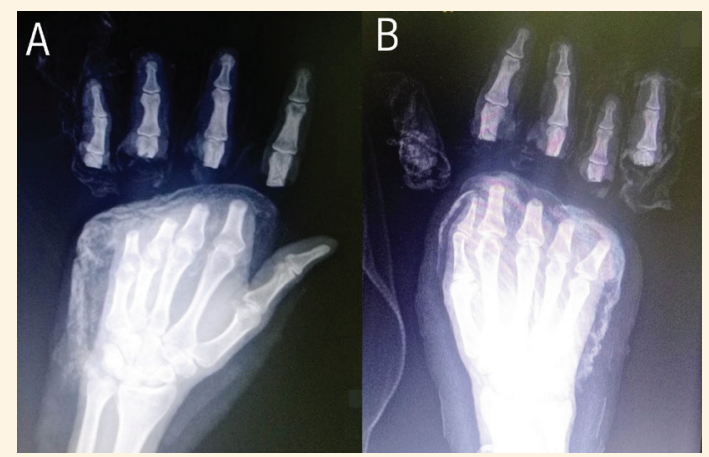

Figure 2: X-ray images of multi-finger amputations on the (A) left and (B) right hand of a 41-year-old male patient showing the levels of amputation through the proximal phalanges.

The fingers perfused immediately following replantation. There was a significant amount of blood loss during the latter part of the operation, possibly due to the heparin injection given when the arterial clamps were released. The wounds continued to ooze postoperatively and the patient was monitored in the intensive care unit (ICU) for the following 48 hours where he received a total of eight units of blood transfusion including the intraoperative and postoperative period. His coagulation parameters were monitored throughout this period. All the fingers were perfusing well until the fourth postoperative day, when the ring and little fingers on the right hand gradually became congested. By the time the patient had to leave the country, the perfusion of these two fingers was doubtful.

The patient was subsequently treated at a medical college hospital in India, where the little and ring

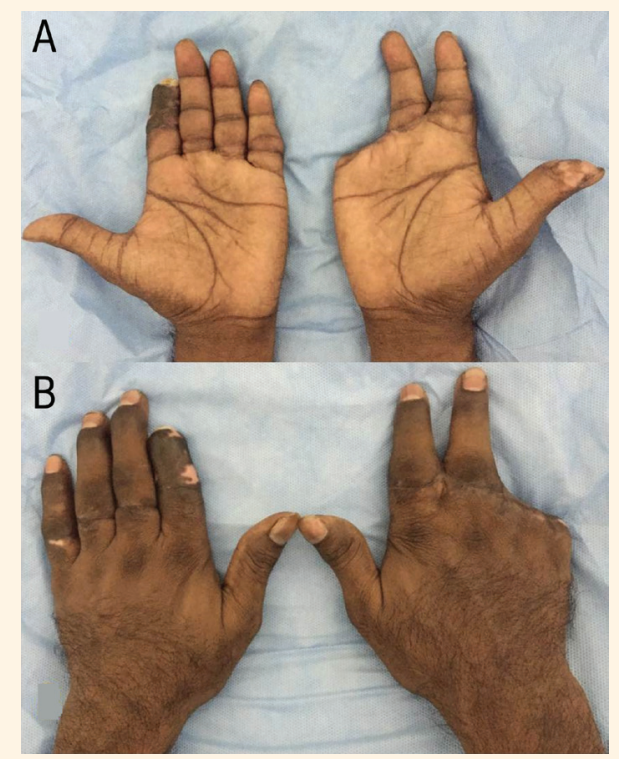

Figure 3: Photographs of both hands of a 41-year-old male patient showing (A) the palmar aspect and (B) the dorsal aspect three years after the replantation surgery. 


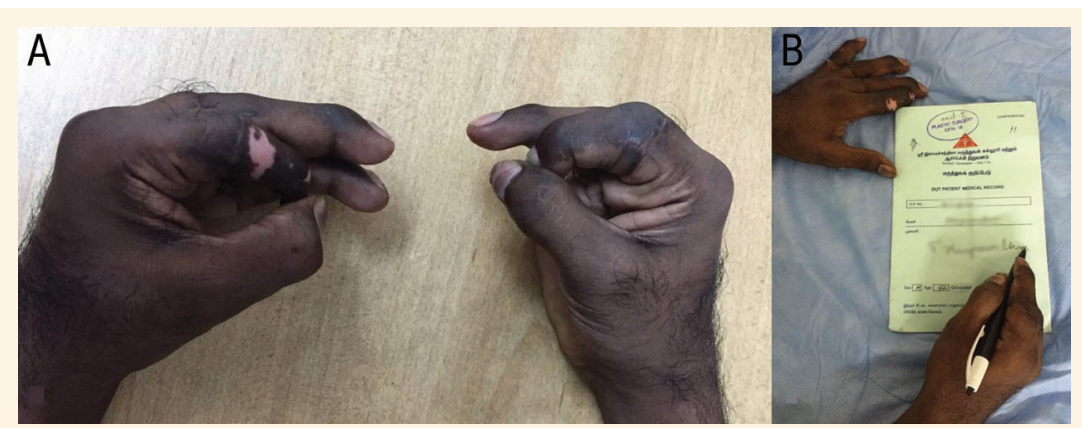

Figure 4: Photographs of both hands of a 41-year-old male patient three years after the replantation surgery showing the functionality of his hands.

fingers of the right hand were terminalised. The left index finger developed a similar congestion followed by skin loss over the volar aspect of the middle phalanx. However, debridement and skin grafts were done to cover the exposed area.

Follow-up was done with the same institute in India and all his wounds have healed well [Figure 3]. He had reasonable functionality of his hands and was able to manage daily tasks [Figure 4]. Additionally, he began working four months following the replantation procedure and was engaged in a meaningful job and was able to support himself and his family during the writing of this report. Three years following the surgery, he was satisfied with the outcome of the procedure. His activities of daily living (ADL) score was $6 / 6$ and instrumental ADL score was $8 / 8$. Overall, he was able to perform all activities reasonably well, with an average total active motion (TAM) for the replanted fingers of approximately 120 degrees. He has good protective sensations with an average static 2 point discrimination of $8-9 \mathrm{~mm}$ at the fingertips. His range of movement can be improved by tenolysis and arthrolysis, as was suggested to him from time to time. However, the patient refused further interventions as he was the sole source of financial support for his family.

\section{Discussion}

The field of microsurgery and replantation has been expanding in recent years. With advances in magnification, instrumentation, sutures and growing experience, more distal amputations are being attempted. While the replantation success rates are improving in some regions, trends in the USA suggest otherwise. ${ }^{6-8}$ There has been a steady decline in replantation attempts due to the fact that fingertip amputations are no longer considered indications for replantation at many centres. ${ }^{8}$ Although, some Asian studies have reported excellent results following replantation for zone 1 amputations, the technical and decision-making aspects of finger replantation are still being discussed..$^{8-12}$ Bilateral multi-finger amputations are fortunately rare and only a few cases have been reported. ${ }^{13-15}$

Ischaemia time is a major concern when dealing with cases of multi-finger amputation. ${ }^{16}$ There should be good communication between the referring team and the receiving team with an emphasis on appropriate preservation of amputated parts, resuscitation of the patient and immediate transfer, which at times may require transport by air. The initial assessment at the receiving centre should be completed by the most experienced team member and should include assessment of the tissue injury both clinically and radiologically. The parts that are functionally important such as the thumb or those that have the best chance of recovery (i.e. minimally crushed fingers and injuries away from joints) should be given priority. If a digit that has a vital function (such as the thumb) is severely damaged, the team should consider replacing it with one of the available amputated fingers with minimal trauma. ${ }^{2,17,18}$

There are two ways to approach a multi-finger replantation where the fingers have been amputated at a similar level and have a similar amount of tissue damage, as is in the present case. First, a "digit by digit" replantation approach can be taken where each finger is reattached one at a time. This approach saves some critical ischaemia time and possibly avoids some blood loss; however, a negative aspect of this approach is that the repaired finger is handled and manipulated repeatedly. Surgeons using this approach must decide the sequence as per the functional importance of a digit and the extent of damage.

Second, a "structure by structure" approach can be used where the surgeon stabilises all fingers followed by repairing the flexor tendons, nerves and then the arteries. Following repair of the volar structures, the hand is turned and the dorsal structures such as the vein and extensor tendons are repaired. This method saves time and avoids manipulation of the digits after replantation, however, it increases ischaemia time as 
all fingers are exposed to warm ischaemia until the revascularisation is complete; there is also the possibility of increased blood loss. ${ }^{1,19}$

Bilateral multi-finger amputation is a rare injury and fortunately adequate resources were available for a simultaneous bilateral surgery. In the current case, a "structure by structure" method was chosen as the patient presented soon after the injury. However, the patient had a significant amount of blood loss which could have been prevented by replanting fewer digits at functionally important positions as a 'damage control measure'; this would have also reduced the total surgical time. Repairing veins before arteries also could have reduced the blood loss that later resulted in haemodynamic instability and an ICU stay.

The patient's bleeding tendency was possibly multifactorial as it may have been caused by the multiple wounds, hypothermia and the lengthy surgery along with multiple blood transfusions. The decline in the perfusion of the fingers, after the fourth postoperative day, may have been due to the patient's coagulation abnormalities and frequent manipulations to change the soaked dressings which may have contributed to the delayed blockage of veins causing congestion and non-survival of two fingers on the right hand.

The functional outcome should be the main criteria for assessing the results of a replantation, not the survival of the fingers. Although the current patient returned to almost normal activity levels and was satisfied with the outcome, the range of motion at the interphalangeal (IP) joints was restricted (average TAM: 120 degrees). The axial Kirschner wires immobilising the IP joints, which was used to achieve quick and stable fixation, may have contributed to the stiffness. Additionally, the patient's inability to attend the physiotherapy clinics and unwillingness for further interventions are also possible causes of residual stiffness.

While attempting salvage procedures following such injuries, patients' expectations should be ascertained. The possible functional outcome and the timeframe for recovery should be clearly discussed with the patient. In addition, it is essential that an informed consent be obtained before proceeding with any procedure to avoid any liability. ${ }^{19}$

\section{Conclusion}

Multi-finger amputation is an important indication for replantation as salvaged fingers can contribute towards improving the overall hand function. Close observation of patients' vitals and coagulation parameters is important during the intra- and postoperative periods. Multiple teams of trained surgeons with experience in digital level replantation should be available to help overcome fatigue and improve overall efficiency and success of the procedure, which would ultimately improve the outcome for the patient.

\section{ACKNOWLEDGEMENT}

The authors would like to acknowledge Dr J. Satish Kumar, Senior Consultant at the Sri Ramachandra Medical College, Chennai, India, for following-up the patient, recording the necessary clinical data and providing his feedback.

\section{References}

1. Pederson WC. Replantation. Plast Reconstr Surg 2001; 107:823-47. https://doi.org/10.1097/00006534-200103000-00027.

2. Chim H, Maricevich MA, Carlsen BT, Moran SL, Salgado CI, Wei FC, et al. Challenges in replantation of complex amputations. Semin Plast Surg 2013; 27:182-9. https://doi.org/10.1 055/s-0033-1360585

3. Salah MM, Khalid KN. Replantation of multiple digits and hand amputations: Four case reports. Cases J 2008; 1:266. https://doi. org/10.1186/1757-1626-1-266.

4. Baek SM, Kim SS. Ten-digit and nine-digit replantation (4 cases). Br J Plast Surg 1992; 45:407-12. https://doi.org/10.1016/00071226(92)90202-9.

5. Chung KC, Alderman AK. Replantation of the upper extremity: Indications and outcomes. J Hand Surg Am 2002; 2:78-94. https://doi.org/10.1053/jssh.2002.33319.

6. Kwon GD, Ahn BM, Lee JS, Park YG, Ha YC. Clinical outcomes of a simultaneous replantation technique for amputations of four or five digits. Microsurgery 2016; 36:225-9. https://doi.org/10.1 002/micr.30009.

7. Woo SH, Cheon HJ, Kim YW, Kang DH, Nam HJ. Delayed and suspended replantation for complete amputation of digits and hands. J Hand Surg Am 2015; 40:883-9. https://doi.org/10.10 16/j.jhsa.2015.01.006.

8. Reavey PL, Stranix JT, Muresan H, Soares M, Thanik V. Disappearing digits: Analysis of national trends in amputation and replantation in the United States. Plast Reconstr Surg 2018; 141:e857-67. https://doi.org/10.1097/prs.0000000000004368.

9. Hattori Y, Doi K, Ikeda K, Estrella EP. A retrospective study of functional outcomes after successful replantation versus amputation closure for single fingertip amputations. J Hand Surg Am 2006; 31:811-18. https://doi.org/10.1016/j.jhsa.20 06.02.020.

10. Sebastin SJ, Chung KC. A systematic review of the outcomes of replantation of distal digital amputation. Plast Reconstr Surg 2011; 128:723-37. https://doi.org/10.1097/prs.0b013e3182 $21 \mathrm{dc} 83$

11. Chiu HY. [Indications and contraindications of digital replantation]. J Formos Med Assoc 1992; 91:S214-21.

12. Barbary S, Dap F, Dautel G. Finger replantation: Surgical technique and indications. Chir Main 2013; 32:363-72. https://doi.org/10.1016/j.main.2013.04.012.

13. Baek SM, Kim SS. Ten-digit and nine-digit replantation (4 cases). Br J Plast Surg 1992; 45:407-12. https://doi.org/10.1016/00071226(92)90202-9. 
14. Kim WK, Lee JM, Lim JH. Eight cases of nine-digit and ten-digit replantations. Plast Reconstr Surg 1996; 98:477-84. https://doi. org/10.1097/00006534-199609000-00018.

15. Kantarci U, Cepel S, Buldu H. Successful replantation in tendigit amputation. Acta Orthop Traumatol Turc 2010; 44:76-8. https://doi.org/10.3944/aott.2010.2109.

16. Zumiotti A, Ferreira MC. Replantation of digits: Factors influencing survival and functional results. Microsurgery 1994; 15:18-21. https://doi.org/10.1002/micr.1920150107.
17. Zenn MR, Scott L. Chapter 15 - Multiple-Digit Replantations. In: Weinzweig N, Weinzweig J, Eds. The Mutilated Hand. Amsterdam, Netherlands: Elsevier, 2005; Pp. 217-24.

18. Koul AR, Patil RK. Thumb Reconstruction. In: Textbook of Plastic, Reconstructive, and Aesthetic Surgery: Volume II: Hand and Upper Extremity. Delhi, India: Thieme, 2017. Pp. 457-92.

19. Tang JB, Wang ZT, Chen J, Wong J. A global view of digital replantation and revascularization. Clin Plast Surg 2017; 44:189-209. https://doi.org/10.1016/j.cps.2016.11.003. 